\title{
Complete Circularity in Cross-Laminated Timber Production
}

\author{
Ilze VAMZA ${ }^{1}$, Karlis VALTERS ${ }^{2}$, Ilze LUKSTA ${ }^{3}$, Peteris RESNAIS ${ }^{4}$, \\ Dagnija BLUMBERGA ${ }^{5}$ \\ ${ }^{1-3,5}$ Institute of Energy Systems and Environment, Riga Technical University, Azenes iela 12/1, \\ Riga, LV-1048, Latvia \\ ${ }^{4}$ SIA FUNDUSS, 'Tiltakrogs”, Ieriḳi, Drabešu parish, Amatas reg. LV-4139, Latvia
}

\begin{abstract}
Many authors have discussed the paradigm shift in economy from linear to circular. Population growth and climate change caused resource scarcity are the main driving forces of shifting to circularity approach. Although consumers have been slower regarding transitioning to more sustainable economy, production companies are the ones who have felt the scarcity of resources first. In this paper we are exploring cross-laminated timber (CLT) production residue utilization possibilities for new product production and using multicriteria analysis calculating the most promising recycling alternative from the perspective of companies working with wood as raw material. Data matrix for multi-criteria analysis was constructed from literature analysis gathering data on five criteria: (1) production costs; (2) energy consumption; (3) $\mathrm{CO}_{2}$ emissions; (4) product market price and (5) final product to wood residues ratio. Multi-criteria analysis showed that production of mycelium insulation material is the most promising alternative for CLT production residue recycling.
\end{abstract}

Keywords - Cascades; green growth; multi-criteria analysis; sustainable building; wood residue

\begin{tabular}{|lll}
\hline Nomenclature & - \\
$S M E$ & Small and medium enterprise & - \\
$C L T$ & Cross-laminated timber & - \\
$P W H$ & Peat, woodchip, and hemp shave composite & - \\
$M D F$ & Medium density fiberboard & - \\
$H D F$ & High density fiberboard & - \\
$P B$ & Particleboard & - \\
$\mathrm{CO}_{2 \mathrm{eq}}$ & Carbon dioxide equivalent & - \\
$A H P$ & Analytical hierarchy process & - \\
$T O P S I S$ & Technique for Order of Preference by Similarity to Ideal Solution & - \\
$U F$ & Urea-formaldehyde & -
\end{tabular}

* Corresponding author.

E-mail address: Ilze.Vamza@rtu.lv 


\section{INTRODUCTION}

Circularity principles in economy are gaining momentum with The Paris Agreement [1] and the European Green Deal [2]. United Nations in their 2011 report advocated that decoupling of economic growth from resource consumption along with the negative impact on environment is a key to sustainable future. Every region has its limits on how much natural resources can be extracted, nevertheless all nations have the desire to grow and develop [3]. It comes down to consumers and production companies to make more sustainable choices and work on resource efficiency [4]. Bocken et al. in her 2017 commentary published 9-year keyword analysis on major global companies' press releases, showing the gradual appearance of words like 'zero-waste' and 'resource efficiency' [5]. Recent analysis on how small and medium enterprises (SME) participate in the circular economy elucidated eight approaches, with the main six:

- Maximize efficiency and productivity of material and energy;

- Increase the proportion of bio-based and renewable material use;

- Create value from waste;

- Develop industrial symbioses and transparent supply chains;

- Encourage sufficiency;

- Develop scale-up solutions [6].

For the SME to be able to adopt the abovementioned approaches research and development is required. Another study by Zihare et al. elucidate the complex network of factors impacting bioeconomy - network illustrates the links between research and development, technology, and bioresource [7]. Another important driving force of innovation is policies [4], [7]. Major sector regarding resource consumption is building sector. Global efforts are aimed towards reduction of impact of building construction, exploitation and demolition [8]. Important aspects in greener building, especially in construction phase, is the choice of materials materials made from bio-based raw materials [6], lightweight and easy to use materials result in faster production times, reduction of overall impact of construction phase on the environment [9]. National efforts of transition to greener building process include various policies with varying tools in the form of stimulus or incentives. Nevertheless, it often comes down to material producers and project developers to invest in green innovations, often encouraged by social demand [8], [10]. It is important not only to create greener supply chains of renewable raw material but to use the created production residues in other economic activities, hence promoting resource efficiency [11]. Resource cascading principles imply reuse, recycling, and recovery in the described order. When possible, production residues should be reused as a raw material for the same product production where they were generated. In this way the demand for new raw material would be reduced. If there are technological limitations for production residues to be reused, they can be recycled transferred to a relevant recycling company or a company that can use it as raw material. Recovery should be used only as a last resort when nothing else other than energy recovery is possible [12]. Recycling is part of open-loop lifecycle - on this basis industrial synergies can be created. Depending on the material, receiving companies may need to acquire license for accepting waste in their plant [13].

Regarding building industry's circularity (and sustainability) wood is still one of the most promising raw materials. Although used for many centuries, wood has regained its popularity due to its sustainability and physical properties [10]. Deeper understanding of the mechanics behind timber strength along with stronger binders [14], [15] have led to engineered wood products like fiberwood, particleboards, laminated beams [16] and cross-laminated timber (CLT) [17]. 
CLT is a promising construction material, its mechanical properties and renewable raw material makes it attractable mineral building block replacement [17]. With today's technology it is possible to build midrise buildings using renewable laminated wood constructions [9]. Building with CLT is a fast process due to its pre-fabrication possibilities. CLT panels are made by gluing wooden planks together in cross-wise manner, as a result large panels can be made and cutouts for openings like doors and windows can be made in production plant, this approach makes working on site much easier. The downside of this prefabrication is the generated cuttings - around $20 \%$ of CLT panels are entering production residue streams. Our previous work explored the environmental impact and possibilities of reusing CLT cuttings for new CLT panel production. With the developed CLT reprocessing technology, around $70 \%$ of the generated cuttings can be reused for new full-size panel production [18]. Work shows how industrial innovation would be applied in CLT production plants allowing for CLT producers to operate in line with the circular economy principles [12]. Nevertheless, to develop a full cascade for CLT production, it is crucial to explore the possibilities for CLT residue recycling. As specific research on CLT residues have not been done, in this work we will explore the options for other wood residue utilization.

CLT residues comprise sawdust from cutting and finger-jointing, and cuttings made from cross-wise laminated planks. These larger cuttings (Fig. 1) have around $2 \%$ of adhesive. Today CLT is mainly produced using urea-formaldehyde (UF) or polymer iso-cyanine adhesives like polyurethane [17]. UF resins cause toxic fumes, hence the use of polyurethane can reduce the negative impact of the final product [19]. In addition, fatty acids in polyurethane production can be replaced by renewable canola oil [17] reducing the negative environmental impact of polyurethane itself.

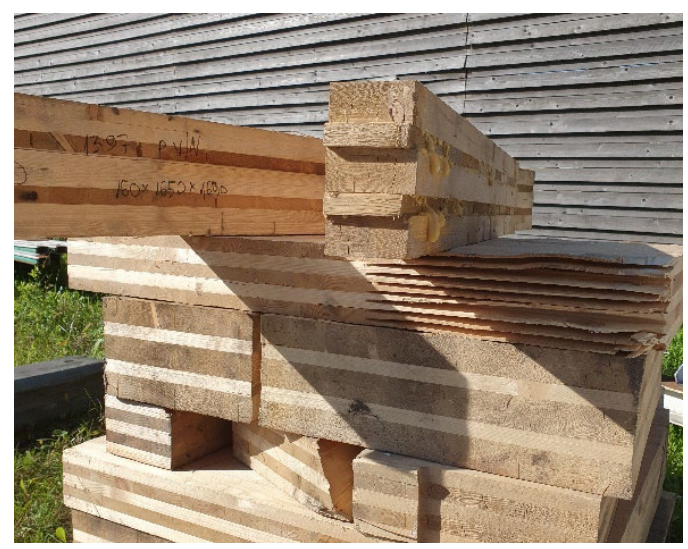

Fig. 1. Cross laminated timber non-reusable cuttings.

With the emerging paradigm shift in economy from linear to circular [11], [20], [21], it is necessary to work on full circularity of products. This research explores the possibilities for full circularity of CLT production, ensuring recycling of production residues unsuitable for reuse. In this paper we are exploring CLT production residue utilization alternatives for various product production and using multi-criteria analysis to elucidate the most promising one from the perspective of companies working with wood products. 


\subsection{Materials from Wood Residues}

Using production residues when primary raw material runs out is not anything new, wood particleboards were mass produced during World War II when supply for sawn wood could not meet the demand [22]. To achieve similar structural integrity to sawn wood, wood particles are bonded together with formaldehyde, urea or phenolic resins. Despite formaldehyde's toxicity UF resin is the one that is most often used and particleboards are the most popular wood-based composite [23]. Consumer demand for particleboards have made this industry so profitable that good quality timber was used as raw material. Research have shown that recycled wood raw material negatively impacts the mechanical strength of the final product [24]. Only in recent decade companies are looking into steering away from timber to wood residue as raw material [24], [25]. Lumber is the preferred choice of raw material because it can be broken down into particles with necessary geometry and size. Wood residues usually come in various forms - sawdust, dust or woodchip. Research have shown that larger particles than sawdust are preferable in order to achieve better mechanical strength of particleboard [26].

Popular wood-based panels are medium (MDF) and high (HDF) density fiberboards. Annually around 9 million $\mathrm{m}^{3}$ of fiberboards are produced in European Union alone [27]. Fine cellulose fibers are glued together with UF resin [28]. To acquire the cellulose fiber, wood is treated using thermo-mechanical pulping during which cellulose is separated from lignin. The overall strength of wood is compromised when lignin absorbs water, making it easier to separate cellulose from lignin with mechanical force. Thermomechanical pulping is carried out at $\sim 180{ }^{\circ} \mathrm{C}$ temperatures and $60-120 \%$ humidity [29]. After fiber refining they are dried to around $7 \%$ water content [28].

Typically, MDF is made from production residues (e.g. green and dried sawdust, veneer and plywood cuttings) of primary wood products - lumber and plywood. As plywood is made from veneer sheets glued with UF resin in a cross-wise manner [28], [30] it can be speculated that CLT cutting residues could be used for MDF production despite the varying directions of wood grain.

Another material where wood residues can be used is thermal insulation composite of peat, woodchip and hemp shaves (PWH) [31]. Material has been tested in laboratory setup on heat conductivity, showing 0.056 to $0.060 \mathrm{~W} /(\mathrm{m} \cdot \mathrm{K})$ thermal conductivity. Benefits of this technology implies that less energy is needed to produce it in comparison to medium density fiberboards (MDF) or mineral wool. Curing $\mathrm{PWH}$ requires only $75^{\circ} \mathrm{C}$ [31] temperatures where MDF requires $175^{\circ} \mathrm{C}$ [32], nevertheless, PWH requires 24 hours of $75{ }^{\circ} \mathrm{C}$ but MDF only 275 seconds [31], [32] resulting in 3.36 MWh versus $0.02 \mathrm{MWh}$ respectively. Another thermal insulation material made from wood residue is mycelium based, with its first iterations material was made from agricultural residues by cultivating specific fungi on it. In addition to material's excellent thermal conductivity of $0.039 \mathrm{~W} /(\mathrm{m} \cdot \mathrm{K})$, its light weight, mycelium insulation material can be produced using less energy than PWH or conventional mineral wool insulation as solar dryers can supply sufficient amount of energy for curing the material [33].

Physical properties of wood make it an attractive building material, it can be used on its own, for example in log houses [34], or as engineered wood in a form of a CLT [35] or in composites as described above with thermal insulation material [31]. Relatively low density of wood and its thermal properties makes it an excellent filler as wood ignition temperature is in the range of temperatures used for brick burning. Burning bricks to cure them result in sawdust filler burning, as a result density of the mineral blocks decreases, reducing the dead load of final construction [36]. Heavy building loads are a safety issue in regions within 
Earth's earthquake zones [36], in regions like Latvia reduced material weight leads to lower emissions during construction phase as less energy is needed for transportation [37] and other manipulations with the material. Recently researchers have been exploring the benefits of polypropylene and wood composite materials. By placing the wood sawdust in specific areas, material with disparate stiffness in its sections can be achieved. At this point it is expected that this kind of material could be used in snap fit parts in connections or quick release parts [38]. This kind of parts could be used in products compliant with eco-design principles [39] replacing polypropylene with biodegradable plastic like polylactic acid.

Solid fuel in the form of wood pellets can be produced from various wood residues [40]. Although, wood burning is considered more sustainable, it generates considerable amount of $\mathrm{CO}_{2}$ emissions. Each generated GJ of energy from wood pellets releases $11.76 \mathrm{~kg} \mathrm{CO}_{2} \mathrm{eq}$ in the atmosphere [41].

In line with the European Union's Green Deal and global trends of circular economy and resource efficiency, it is important for companies developing new products to utilize their production residues in the best possible way. In this work we are exploring potential opportunities for CLT cutting recycling into four alternatives - medium density fiber-board, mycelium thermal insulation material, particleboard, or solid fuel. All the alternatives have their benefits and downfalls, hence multi-criteria decision making tools will be utilized in order to find the best alternative. Our goal is to elucidate the best possible alter-native for CLT cutting use according to expert opinions and literature analysis.

\section{MATERials AND MethodS}

\subsection{Criteria and Data Gathering}

Products were analysed from green economy perspective, hence criteria that would represent it was chosen. Overall, five criteria:

1. Production costs;

2. Energy consumption;

3. $\mathrm{CO}_{2}$ emissions;

4. Product market price;

5. Final product to wood residues ratio were chosen.

Values for analysed criteria were gathered from scientific literature, market data [42] and life cycle inventories [43], [44] on the chosen products.

Production costs included energy, raw material, and labour costs to produce one metric ton of the product. Energy consumption and $\mathrm{CO}_{2}$ emissions during production process of one metric ton of product was calculated from energy consumption and source (grid or cogeneration). 'New product to raw material' criterion represented the extra material needed for the production of new product (one of alternatives). Ratio of new product to raw material also represented how much of the raw material originally used for production could be replaced with wood resides. Product market price represents value what the consumer pays to acquire the material from market.

Data were gathered from life cycle inventories and other works. In case of life cycle inventories of $\mathrm{PB}$ and MDF data were reflected using functional unit or one square meter, hence values were converted to tonne using material density.

\subsection{Multi-Criteria Decision Making}

Many multi-criteria decision-making (MCDM) methods have been developed to provide decision makers with tools based on mathematical logic. All MCDM methods have some 
subjectivity aspect to them and many MCDM methods provide different results as shown by Zlaugotne et al. [45] Siksnelyete et al. recognized Technique for Order of Preference by Similarity to Ideal Solution (TOPSIS) method as the one having the most benefits in comparison to PROMETHEE, PROMETHEE II, VIKOR, WASPAS, WASPAS-G and Fuzzy Sets. AHP had the second best benefit count [46]. In addition, Lee et al. 2012 have used AHP specifically for technology transfer adoption in companies, hence showing the compatibility of AHP to organizational decision making [47]. In this work we are looking for the best alternative closest to the ideal solution, hence TOPSIS was chosen in combination with AHP. TOPSIS method not only elucidates the best alternative but gives the closeness to the ideal solution coefficient [48]. Hence, by using TOPSIS more detailed picture of 'How ideal all the alternatives are' can be acquired. To acquire weights for TOPSIS, Analytical hierarchy process (AHP) was used. AHP is one of the most widely used MCA methods because it allows to easily compare criteria with each other [49]. In this work, the Saaty's scale was used to compare the criteria, in which nine degrees of importance were verbally denoted, indicating the importance of one criterion over another. The scale of nine ratings starts with 1, which stands for equal importance, and ends with 9 which stands for extreme importance [50].

To evaluate the importance of each criterion, experts with experience on CLT production were asked to rate reciprocal relations of criteria. For evaluation, experts were acquainted with Saaty's scale and criteria plotted in Excel to generate questionnaires for experts to fill. Questionnaires were sent out via e-mail.

The acquired ranking was used in AHP in order to calculate the normalized eigenvectors representing the importance of each criterion [50]. Criteria and their ranking were plotted in Excel in a comparison matrix as shown by Delvere et al. [51]. Consistency ratio $<0.2$ was determined, and the calculated weights were used in further MCA.

AHP was used in combination with TOPSIS.

TOPSIS decision-making method was based on previously calculated weights for AHP, and data collected from the literature. Four alternatives for CLT residue utilization were considered:

- MDF;

- Mycelium insulation;

- Solid fuel;

- PB.

For comparison, the considered alternatives and their criteria were arranged in a decisionmaking matrix and the matrix data were normalized, Eq. (1).

$$
\begin{aligned}
& A_{1} \\
& A_{2} \\
& A_{3} \\
& A_{4}
\end{aligned}\left[\begin{array}{llll}
v_{11} & v_{12} & v_{13} & v_{14} \\
v_{21} & v_{22} & v_{23} & v_{24} \\
v_{31} & v_{32} & v_{33} & v_{34} \\
v_{41} & v_{42} & v_{43} & v_{44}
\end{array}\right],
$$

where $A_{n}$ alternative uses of wood residue, $v_{n}$ criteria, normalized matrix.

The obtained normalized values were multiplied by the weights obtained by AHP and the distance of each criterion to the ideal solution was determined.

Sensitivity analysis was conducted to evaluate robustness of the TOPSIS results. To compare sensitivity of the assigned weights $(\omega)$, Li et al. described TOPSIS method was used [52]. Changes in the importance of product market price was calculated by introducing unity variation $\beta \mathrm{pm}$ that represents the changes in product market price weight. After changes the 
product market price weight $(\omega$ 'pm), all the other criteria weights $(\omega)$ were recalculated according to:

$$
\left\{\begin{array}{c}
\omega_{1}^{\prime}=\frac{\omega_{1}}{1+\left(\gamma_{\mathrm{pm}}-1\right) \cdot \omega_{\mathrm{pm}}} \\
\omega_{\mathrm{pm}}^{\prime}=\frac{\omega_{\mathrm{pm}} \cdot \gamma_{\mathrm{pm}}}{1+\left(\gamma_{\mathrm{pm}}-1\right) \cdot \omega_{\mathrm{pm}}} \\
\omega_{\mathrm{n}}^{\prime}=\frac{\omega_{\mathrm{n}}}{1+\left(\gamma_{\mathrm{pm}}-1\right) \cdot \omega_{\mathrm{pm}}}
\end{array}\right.
$$

where

$\omega^{\prime}$ pm Product market price criteria weight after changes;

$\omega^{\prime}$ n Other criteria weights after changes in $\omega_{\mathrm{pm}}$;

$\gamma_{\mathrm{pm}}$ Initial variation, calculated according to:

$$
\gamma_{\mathrm{pm}}=\frac{\beta_{\mathrm{pm}}-\beta_{\mathrm{pm}} \cdot \omega_{\mathrm{pm}}}{1-\beta_{\mathrm{pm}} \cdot \omega_{\mathrm{pm}}},
$$

where $\beta_{\mathrm{pm}}$ unity variation, calculated according to:

$$
\beta_{\mathrm{pm}}=\frac{\omega_{\mathrm{pm}}^{\prime}}{\omega_{\mathrm{pm}}} .
$$

In addition, sensitivity on the production costs of the ideal CLT cutting recycling alternative was conducted.

\section{Results}

Based on the conducted AHP weights for criteria of wood residue, recycling was calculated and used in TOPSIS analysis to elucidate the best alternative from companies working with CLT perspective.

According to expert evaluation, production costs are the most important when considering potential applications of wood residue. Production costs are followed by product market price, and wood residue to new product ratio. Results of AHP are shown in Fig. 2.

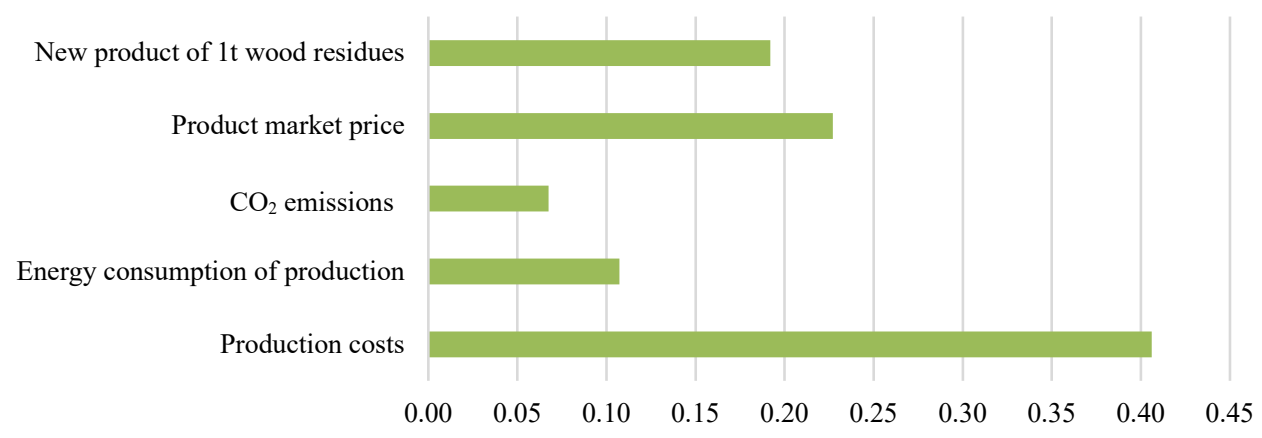

Fig. 2. Weighed criteria. Weights of criteria are determined using analytical hierarchy process un input form expert interviews. The sum of all weights is equal to 1 . 
Calculated weights were used for TOPSIS analysis as described in section 2. Data matrix of alternatives and their corresponding criteria are depicted in Table 1. along with calculated weights.

TABle 1 . Data MatriX With CONSIDERED Alternatives $\left(A_{\mathrm{N}}\right)$ AND CORRESPONDING DATA of WEIGHED CRITERIA $\left(X_{\mathrm{N}}\right)$

\begin{tabular}{|c|c|c|c|c|c|c|}
\hline & $\begin{array}{l}\left(x_{1}\right) \text { Production } \\
\text { costs }\end{array}$ & $\begin{array}{l}\left(x_{2}\right) \text { Energy } \\
\text { consumption }\end{array}$ & $\begin{array}{l}\left(x_{3}\right) \mathrm{CO}_{2} \\
\text { emissions }\end{array}$ & $\begin{array}{l}\left(x_{4}\right) \text { Product } \\
\text { market price }\end{array}$ & $\begin{array}{l}\left(x_{5}\right) \text { New product to } \\
\text { wood waste ratio }\end{array}$ & \\
\hline Criteria weights $(\omega)^{1}$ & 0.41 & 0.11 & 0.07 & 0.23 & 0.19 & Reference \\
\hline Units & $€ /$ tonne & $\mathrm{MWh} / \mathrm{t}$ & $\mathrm{kg} \mathrm{CO}_{2} / \mathrm{t}$ & $€ /$ tonne & $\mathrm{t}$ & \\
\hline $\begin{array}{l}\left(A_{1}\right) \text { Medium density } \\
\text { fiberboard }\end{array}$ & 250 & 1.6 & 1088 & 586 & 0.9 & {$[42],[44]$} \\
\hline $\begin{array}{l}\left.A_{2}\right) \text { Mycelium } \\
\text { insulation material }\end{array}$ & 68 & 0.28 & 47 & 140 & 0.9 & {$[42],[53]$} \\
\hline$\left(A_{3}\right)$ Solid fuel & 113 & 0.02 & 38 & 204 & 1 & {$[42]$} \\
\hline$\left(A_{4}\right)$ Particle boards & 147 & 0.77 & 150 & 350 & 0.9 & {$[42]$} \\
\hline
\end{tabular}

Note: ${ }^{1}$ Weights calculated with analytical hierarchy process approach.

TOPSIS approach elucidated the mycelium thermal insulation material as the most promising wood residue utilization option and MDF production as the least preferable option (Fig. 3). Mycelium thermal insulation gained closeness coefficient (CC) of 0.65 to the ideal solution. According to expert evaluation and literature data, solid fuels gained $\mathrm{CC}$ of 0.59 showing that solid fuel production is still closer to ideal than non-ideal solution. Nevertheless, when raw material cascades are considered, burning the by-product is considered as the least preferable option, especially if the by-product could still be recycled for other purposes [12].

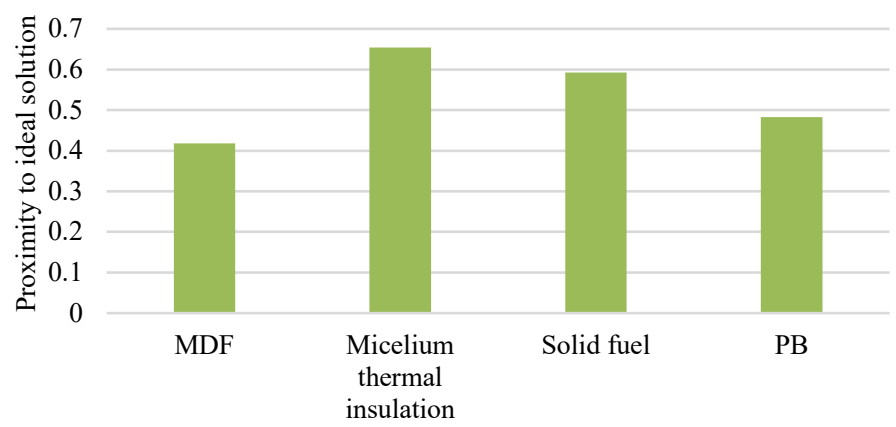

Axis Title

Fig. 3. Multi-criteria analysis results, showing options considered and their proximity to the most preferable alternative represented on y-axis. (PB-particleboard; MDF- medium density fiberboard).

Sensitivity analysis of criteria weight showed the similarity of two preferable options mycelium thermal insulation and solid fuel. By changing the weight of product market price according to unity variation $\beta_{\mathrm{pm}}$, mycelium thermal insulation material and solid fuel alternatives experienced the same trend. When the weight of product market price doubles, these two alternatives lose their positive proximity to the ideal solution. MDF experience mirrored trend to mycelium thermal insulation and solid fuel alternatives, but PB is the least impacted by the changes in product market price. 


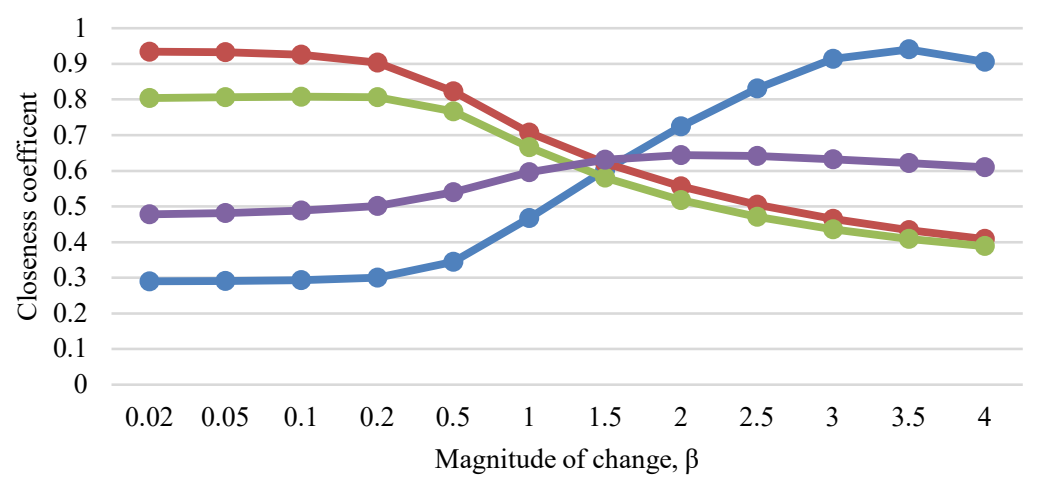

$\longrightarrow$ Medium density fibreboard $\longrightarrow$ Mycelium thermal insulation
- Solid fuel

Fig. 4. TOPSIS results sensitivity analysis. Sensitivity analysis is conducted by changing weight of product market price and re-calculating the rest of assigned weights. X-axis depicts magnitude $(\beta)$ of change of product market weight and $\mathrm{y}$-axis depicts the closeness coefficient of all alternatives to the ideal solution.

Additional sensitivity analysis on product market price change was conducted to evaluate how the most ideal alternative - mycelium thermal insulation material's closeness coefficient to the ideal solution and how the closeness coefficient of other alternatives would be impacted. A step of $10 \%$ change was chosen and results are depicted in Fig. 5. Despite of the product market price reduction of $50 \%$, mycelium thermal insulation was still the most preferable alternative, gaining greater distance from the second best alternative - solid fuel.

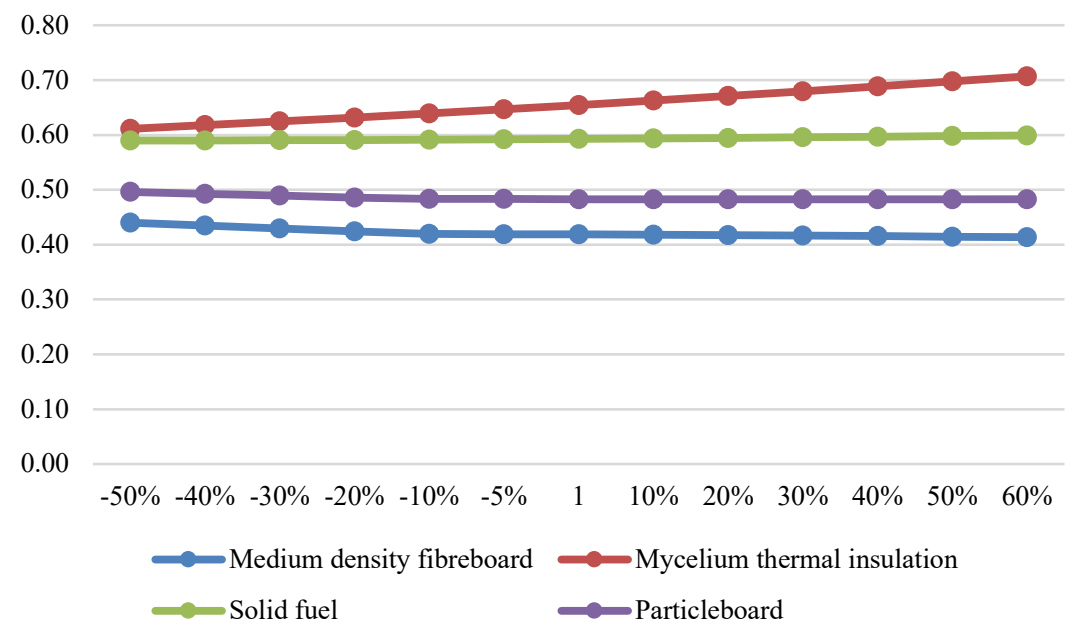

Fig. 5. Sensitivity analysis on mycelium thermal insulation's market price change on the closeness coefficient to the ideal solution change.

As production costs were the only criterion where mycelium thermal insulation material took the lead from the start, sensitivity analysis was conducted to find out how big should be the changes in mycelium thermal insulation production for the material to lose its most 
preferred rank. Sensitivity analysis on mycelium thermal insulation production cost (depicted in Fig. 6) show that $60 \%$ increase on production costs would make mycelium alternative less desirable as solid fuel production.

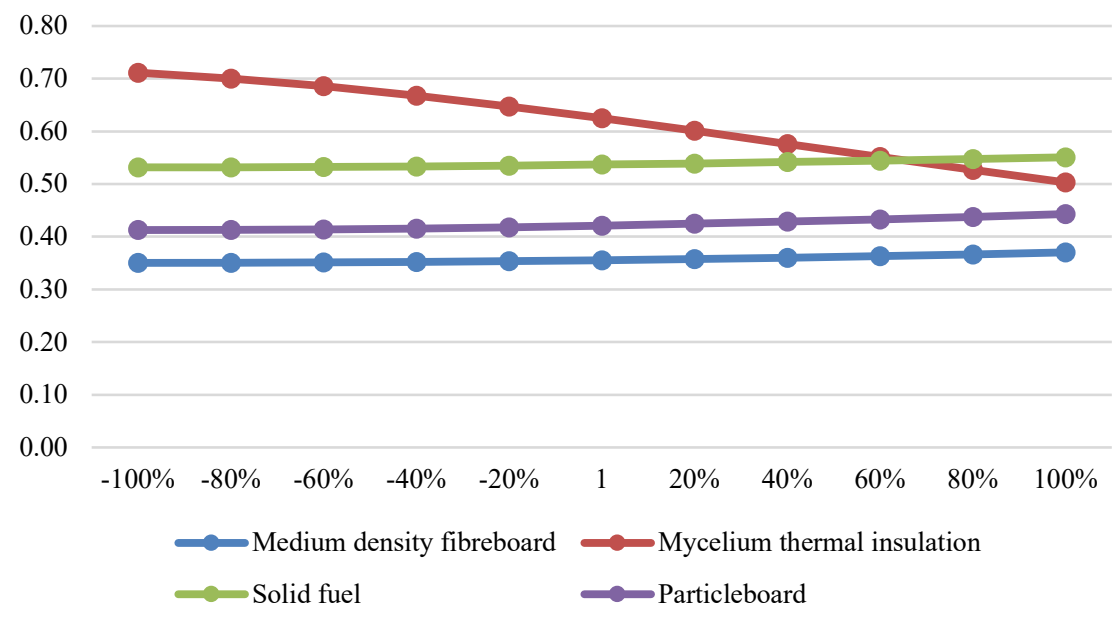

Fig. 6. Sensitivity analysis on mycelium thermal insulation's production cost changes.

\section{Discussion}

Objectives of this paper was to conduct literature analysis on existing wood residue recycling technologies and compare them from the perspective of the company generating CLT residues. Although specific CLT residue utilization alternatives have not yet been published, in this paper we explored known wood residue utilization options. PB and MDF alternatives had closest proximity to un-ideal solution when analysed from the perspective of $\mathrm{CO}_{2}$ emissions and economy. In addition, there might be technical limitations of CLT recycling into specific dimensions of chips and fibers due to heterogeneous nature of CLT layers [17].

Conducted analysis showed that the most energy intensive solution - MDF production, is the least preferable one as well. Energy intensive production process is reflected in $\mathrm{CO}_{2}$ emissions more than seven times higher than $\mathrm{PB}$ production, this is due to the required MDF setting temperatures that are $20^{\circ} \mathrm{C}$ higher in comparison to $\mathrm{PB}$ production. In addition, wood fiber separation required steam, making it energy and water intensive process.

Amongst considered alternatives for wood residue use the mycelium insulation material was recognized as the best, despite it having the most preferable result only in one criterion - production costs. According to sensitivity analysis, production costs of mycelium thermal insulation material would need to increase by $60 \%$ in order for it to lose its preferability over solid fuel production. As a second best alternative solid fuel was elucidated. It is understandable as wood pellet production requires almost no other raw material and relatively small energy consumption. Nevertheless, wood pellets generate $205.8 \mathrm{~kg}$ of $\mathrm{CO}_{2}$ emissions per tonne during exploitation. On the contrary, the rest of considered alternatives provide carbon storage during their exploitation phase. As shown in the introduction of this paper, energy recovery is the very last step in cascading. To make the CLT production as sustainable as possible, production residues should be recycled if possible. In case of mycelium insulation 
material, it could be used for energy recovery at its end-of-life cycle, as a result prolonging CLT residue life cycle.

This research provides insights into promising CLT residue recycling options. Although MCA elucidated mycelium insulation material the most promising alternative, practical research is needed to test capabilities of various fungi to grow on timber with polyurethane residues.

\section{ACKNOWLEDGEMENT}

Funding: This research was carried out with the support of CFLA contract No. 1.2.1.1/18/A/004 between 'Forest Sector Competence Centre of Latvia' Ltd. and the Central Finance and Contracting Agency, the study is conducted by 'FUNDUSS' Ltd. with support from the European Regional Development Fund (ERDF) within the framework of the project 'Forest Sector Competence Centre'.

\section{REFERENCES}

[1] UNFCCC. The Paris Agreement [Online]. [Accessed 30.05.2021]. Available: https://unfccc.int/process-andmeetings/the-paris-agreement/the-paris-agreement

[2] EU Commission. The European Green New Deal Annex. J. Chem. Inf. Model. 2013:53(9):1689-1699.

[3] Fischer-Kowalski M., et al. Decoupling Natural Resource Use and Environmental Impacts from Economic Growth. Paris: UNEP DTIE, 2011.

[4] Sanyé-Mengual E., et al. Assessing the decoupling of economic growth from environmental impacts in the European Union: A consumption-based approach. J. Clean. Prod. 2019:236:117535. https://doi.org/10.1016/j.jclepro.2019.07.010

[5] Bocken N. M., Ritala P., Huotari P. The Circular Economy Exploring the Introduction of the Concept Among. J. Ind. Ecol. 2017:21(3):487-490. https://doi.org/10.1111/jiec.12605

[6] D'Amato D., Veijonaho S., Toppinen A. Towards sustainability? Forest-based circular bioeconomy business models in Finnish SMEs. For. Policy Econ. 2020:110:101848. https://doi.org/10.1016/j.forpol.2018.12.004

[7] Zihare L., et al. Triple factor nexus in bioeconomy through indicator analysis. N. Biotechnol. 2020:61:57-68. https://doi.org/10.1016/j.nbt.2020.11.008

[8] Olubunmi O. A., Xia P. B., Skitmore M. Green building incentives: A review. Renew. Sustain. Energy Rev. 2016:59:1611-1621. https://doi.org/10.1016/j.rser.2016.01.028

[9] Jayalath A., et al. Life cycle performance of Cross Laminated Timber mid-rise residential buildings in Australia. Energy Build. 2020:223:110091. https://doi.org/10.1016/j.enbuild.2020.110091

[10] Hildebrandt J., Hagemann N., Thrän D. The contribution of wood-based construction materials for leveraging a low carbon building sector in Europe. Sustain. Cities Soc. 2017:34:405-418. https://doi.org/10.1016/j.scs.2017.06.013

[11] Suzanne E., Absi N., Borodin V. Towards circular economy in production planning: Challenges and opportunities. Eur. J. Oper. Res. 2020:287(1):168-190. https://doi.org/10.1016/j.ejor.2020.04.043

[12] Kalverkamp M., Pehlken A., Wuest T. Cascade use and the management of product lifecycles. Sustain. 2017:9(9):1540. https://doi.org/10.3390/su9091540

[13] Golev A., Corder G. D., Giurco D. P. Barriers to Industrial Symbiosis Insights from the Use of a Maturity Grid. Journal of Industrial Ecology 2014:19(1):141-154. https://doi.org/10.1111/jiec.12159

[14] Alinejad M., et al. Lignin-Based Polyurethanes: Opportunities for Bio-Based Foams, Elastomers, Coatings and Adhesives. Polymers (Basel) 2019:11(7):1202. https://doi.org/10.3390/polym11071202

[15] Magalhães de Souza A., et al. Performance Assessment of OSB Wood Composites with Added Wire Mesh. Int. J. Mater. Eng. 2014:4(3):88-91.

[16] Hemmila V., et al. Development of sustainable bio-adhesives for engineered wood panels - A Review. R. Soc. Chem. 2017:7:38604-38630. https://doi.org/10.1039/c7ra06598a

[17] Brandner R., et al. Cross laminated timber (CLT): overview and development. Eur. J. Wood \& Wood Prod. 2016:74(3):331-351. https://doi.org/10.1007/s00107-015-0999-5

[18] Vamza I., et al. Life Cycle Assessment of Reprocessed Cross Laminated Timber in Latvia. Environ. Clim. Technol. 2021:25(1):58-70. https://doi.org/10.2478/rtuect-2021-0005

[19] Chaudhary A., Messer A. Life cycle assessment of adhesives used in wood constructions Life cycle assessment (LCA) of adhesives used in wood constructions. Zurich: ETH, 2015.

[20] Masi D., et al. Towards a more circular economy: exploring the awareness, practices, and barriers from a focal firm perspective. Prod. Plan. Control 2018:29(6):539-550. https://doi.org/10.1080/09537287.2018.1449246 
[21] Homrich A. S., et al. The circular economy umbrella: Trends and gaps on integrating pathways. J. Clean. Prod. 2018:175:525-543. https://doi.org/10.1016/j.jclepro.2017.11.064

[22] Popescu C. M. Wood as bio-based building material. 2017.

[23] Teixeira D. E., et al. Adhesivity of bio-based anhydrous citric acid, tannin-citric acid and ricinoleic acid in the properties of formaldehyde-free medium density particleboard (Mdp). Drv. Ind. 2020:71(3):235-242. https://doi.org/10.5552/drvind.2020.1917

[24] Iždinský J., Vidholdová Z., Reinprecht L. Particleboards from recycled wood. Forests 2020:11(11):1166. https://doi.org/10.3390/f11111166

[25] Yang T. H., et al. Characteristics of particleboard made from recycled wood-waste chips impregnated with phenol formaldehyde resin. Build. Environ. 2007:42(1):189-195. https://doi.org/10.1016/j.buildenv.2005.08.028

[26] Mirski R., et al. By-products of sawmill industry as raw materials for manufacture of chip-sawdust boards. J. Build. Eng. 2020:32:101460. https://doi.org/10.1016/j.jobe.2020.101460

[27] Eurostat. Medium/high density fiberboard production in EU [Online]. [Accessed 3.06.2021]. Available: https://appsso.eurostat.ec.europa.eu/nui/submitViewTableAction.do

[28] Wilson J. B. CORRIM: Phase II Final Report. Module G Medium Density Fiberboard (MDF): A Life-Cycle Inventory of Manufacturing Panels from Resource through Product. 2008.

[29] Irle M., Thoemen H., Sernek M. Wood-based panel technology: An introduction for Specialists. London: Brunel University Press, 2010.

[30] Wilson J. B., Sakimoto E. T. Gate-to-gate life-cycle inventory of softwood plywood production. Wood Fiber Sci. 2005:37:58-73.

[31] Korjakins A., et al. Application of Peat, Wood Processing and Agricultural Industry By-products in Producing the Insulating Building Materials. J. Sustain. Archit. Civ. Eng. 2013:1(2):62-68. https://doi.org/10.5755/j01.sace.1.2.2884

[32] Gul W., Khan A., Shakoor A. Impact of hot pressing temperature on Medium Density Fiberboard (MDF) performance. Adv. Mater. Sci. Eng. 2017:2017:4056360. https://doi.org/10.1155/2017/4056360

[33] Bruin S. Mycelium: A Building Block for Parkstad Limburg. Delft: Delft University of Technology, 2008.

[34] Grossi P., et al. Analysis of timber log-house construction system via experimental testing and analytical modelling. Constr. Build. Mater. 2016:102:1127-1144. https://doi.org/10.1016/j.conbuildmat.2015.10.067

[35] Epd-Norge.No. Cross laminated timber panels. Oslo: Epd-Norge, 2017.

[36] Ahmed M., et al. Production of Lightweight Bricks Using Saw Dust. Sch. J. Eng. Technol. 2020:8(7):132-140. https://doi.org/10.36347/sjet.2020.v08i07.003

[37] Gurtu A., Searcy C., Jaber M. Y. Emissions from international transport in global supply chains. Manag. Res. Rev. 2017:40(1):53-74. https://doi.org/10.1108/MRR-09-2015-0208

[38] Bahri M. A. S., Ratnam M. M., Khalil H. A. Functionally graded wood filler-recycled polypropylene composite: Effect of mechanical loading on deflection of cantilever beam. Adv. Compos. Lett. 2020:29: 2633366X2092285. https://doi.org/10.1177/2633366X20922856

[39] Luttropp C., Lagerstedt J. EcoDesign and The Ten Golden Rules: generic advice for merging environmental aspects into product development. J. Clean. Prod. 2006:14(15-16):1396-1408. https://doi.org/10.1016/j.jclepro.2005.11.022

[40] Trømborg E., et al. Economic sustainability for wood pellets production - Acomparative study between Finland, Germany, Norway, Sweden and the US. Biomass and Bioenergy 2013:57:68-77. https://doi.org/10.1016/j.biombioe.2013.01.030

[41] Wang C., et al. A life-cycle comparison of the energy, environmental and economic impacts of coal versus wood pellets for generating heat in China A life-cycle comparison of the energy, environmental and economic impacts of coal versus wood pellets for generating heat. Energy 2016:120:374-384. https://doi.org/10.1016/j.energy.2016.11.085

[42] Group A. M. R. Biomass Markets: Weekly biomass markets news and analysis. 2022. [Online]. [Accessed 23.03.2021]. Available: https://www.argusmedia.com/-/media/Files/sample-reports/argus-biomassmarkets.ashx?la=en\&hash=872E2C03A0A78FE3F236BBF00E7729E3114326E0

[43] Rivela B., et al. Life Cycle Inventory of Particleboard: A Case Study in the Wood Sector. J. LCA 2006:11(2):106-113. https://doi.org/10.1065/lca2005.05.206

[44] Rivela B., Moreira M. T., Feijoo G. Life Cycle Inventory of Medium Density Fibreboard. J. LCA 2007:12(3):143-150. http://dx.doi.org/10.1065/lca2006.12.290

[45] Zlaugotne B., et al. Multi-Criteria Decision Analysis Methods Comparison. Environ. Clim. Technol. 2020:24(1):454 471. https://doi.org/10.2478/rtuect-2020-0028

[46] Siksnelyte I., et al. An overview of multi-criteria decision-making methods in dealing with sustainable energy development issues. Energies 2018:11(10):2754. https://doi.org/10.3390/en11102754

[47] Lee S., et al. Using AHP to determine intangible priority factors for technology transfer adoption. Expert Syst. Appl. 2012:39(7):6388-6395. https://doi.org/10.1016/j.eswa.2011.12.030

[48] Ishizaka A., Nemery P. Multi-Criteria Decision Analysis. Methods and software. Wiley, 2013.

[49] Pubule J., et al. Finding an optimal solution for biowaste management in the Baltic States. J. Clean. Prod. 2015:88:214223. https://doi.org/10.1016/j.jclepro.2014.04.053 
[50] Saaty T. L., Sodenkamp M. The Analytic Hierarchy and Analytic Network Measurement Processes: The Measurement of Intangibles: Decision Making under Benefits, Opportunities, Costs and Risks. In Zopounidis C., Pardalos P. (eds) Handbook of Multicriteria Analysis. Applied Optimization 2010:103:91-166. https://doi.org/10.1007/978-3-54092828-7 4

[51] Delvere I., et al. Evaluation of polymer matrix composite waste recycling methods. Environ. Clim. Technol. 2019:23(1):168-187. https://doi.org/10.2478/rtuect-2019-0012

[52] Li P., et al. Sensitivity analysis of TOPSIS method in water quality assessment: I. Sensitivity to the parameter weights. Environ. Monit. Assess. 2013:185(3):2453-2461. https://doi.org/10.1007/s10661-012-2723-9

[53] Jones M., et al. Engineered mycelium composite construction materials from fungal biorefineries: A critical review. Mater. Des. 2020:187:108397. https://doi.org/10.1016/j.matdes.2019.108397 